\title{
Hypoxia inducible factor (HIF) function in innate immunity and infection
}

\author{
Annelies S. Zinkernagel • Randall S. Johnson • \\ Victor Nizet
}

Received: 14 October 2007 / Revised: 25 October 2007 / Accepted: 26 October 2007 / Published online: 21 November 2007

(C) Springer-Verlag 2007

\begin{abstract}
The hypoxia-inducible transcription factor (HIF$1 \alpha)$ is a major regulator of energy homeostasis and cellular adaptation to low oxygen stress. Recently, HIF- $1 \alpha$ has been discovered to function as a global regulator of macrophage and neutrophil inflammatory and innate immune functions, as befits these specialized phagocytic cells who must operate effectively in the hypoxic microenvironments of infected tissues. This review summarizes current knowledge of the role of HIF-1 $\alpha$ in mammalian innate immunity, emphasizing insight gained from conditional gene targeting of the transcription factor in the myeloid cell lineage. Dynamic changes in HIF- $1 \alpha$ expression in the course of bacterial, viral, or parasitic infections are outlined and inferences drawn regarding the consequences for pathogen and host. A better understanding of HIF-1 $\alpha$ function may provide novel and rational approaches for boosting innate immune function in the therapy of certain complicated infectious disease conditions.
\end{abstract}

\footnotetext{
A. S. Zinkernagel $\cdot$ V. Nizet $(\triangle)$

Division of Pediatric Pharmacology \& Drug Discovery, University of California, San Diego School of Medicine, Cellular and Molecular Medicine East, Room 1066, 9500 Gilman Drive, MC 0687,

La Jolla, CA 92093-0687, USA

e-mail: vnizet@ucsd.edu

R. S. Johnson

Division of Biological Sciences, University of California, San Diego,

La Jolla, CA 92093, USA

V. Nizet

Skaggs School of Pharmacy \& Pharmaceutical Sciences, University of California, San Diego,

La Jolla, CA 92093, USA
}

Keywords HIF-1 · Hypoxia · Innate Immunity · Phagocyte · Neutrophil · Macrophage

\section{Introduction}

Microorganisms are omnipresent, colonizing the exterior and interior epithelial surfaces of the human host. This constant interaction leads to many host benefits, for example vitamin production, but also significant disadvantages, such as the risk of infection. To control this fragile balance, the host has evolved a broad arsenal of innate defense mechanisms, including physical barrier functions, soluble effectors such as complement and antimicrobial peptides, and phagocytic cells. The critical role of phagocytes in host defense lies in their rapid mobilization and ability to recognize and inactivate pathogens independent of prior encounter as required by adaptive immunity.

The principal phagocytes of mammalian innate immunity are cells of the myeloid lineage, monocyte/macrophages and neutrophils. These short-lived cells are recruited in response to alterations in tissue integrity, whether the byproduct of chemical or physical injury or the spread of infectious microorganisms. In concert with vasodilation and increased vascular permeability, the activated phagocytes contribute to local inflammation. Tissue foci of inflammation are characterized by low levels of oxygen and glucose, together with high concentrations of lactate and reductive metabolites, including free oxygen radicals $[1,2]$. To maintain energy homeostasis and carry out their biological activities in these specialized environments, phagocytic cell types must generate ATP via glycolysis. Because upregulation of virtually every enzyme in the glycolytic pathway is mediated almost exclusively by the hypoxia-inducible factor- $1 \alpha(\mathrm{HIF}-1 \alpha)$ [3], a role for this transcription factor in 
supporting phagocyte function during inflammation was intuitive. In the last few years, genetic tools provided not only experimental validation of this concept, but uncovered profound implications of the HIF- $1 \alpha$ control pathway in the overall regulation of mammalian innate immunity.

\section{HIF- $1 \alpha$ and myeloid cell inflammation}

HIF-1 is a heterodimeric helix-loop-helix transcription factor whose expression is regulated by oxygen at the protein level. Protein stability of the $\alpha$ subunit (HIF-1 $\alpha$ ) is regulated by a family of oxygen- and iron-dependent prolyl hydroxylases, whose action directs HIF- $1 \alpha$ for degradation by the ubiquitin-proteasome pathway in a process dependent upon interaction with von Hippel-Lindau tumor-suppressor protein (vHL). Under hypoxia, prolyl hydroxylase activity is inhibited, HIF- $1 \alpha$ accumulates and translocates into the nucleus, where it binds the constitutively expressed HIF- $1 \beta$ (aka ARNT). The resultant heterodimer HIF-1 binds to hypoxic response elements (HREs) of target gene regulatory sequences. Classical HIF-1 target genes include the glycolytic enzymes, glucose transporters, erythropoietin, and the angiogenic factor VEGF.

Gene targeting provides invaluable evidence about the function of specific mammalian proteins, but global elimination of HIF- $1 \alpha$ in the mouse produced lethal embryonic defects in vascularization and morphologic development [4-6]. The advent of conditional gene targeting methodologies allowed tissue-specific deletion of floxed HIF- $1 \alpha$ or vHL alleles in the myeloid lineage (macrophages and neutrophils) by crosses into a background of cre recombinase expression driven by the lysozyme M (lysM) promoter. The resultant mice, with either deficient or exaggerated HIF- $1 \alpha$ expression in their phagocytes, are phenotypically normal at baseline but display marked abnormalities when examined in classical models of inflammation [7]. Compared to wild-type mice, HIF-1 $\alpha$ myeloid-null animals have less skin redness and edema after irritation with detergent solution, and greatly diminished joint swelling and cartilage destruction in a passive serum-induced arthritis model [7]. A role for HIF$1 \alpha$ in chronic inflammatory diseases such as rheumatoid arthritis and atherosclerosis is further corroborated by elevated levels of the transcription factor in biopsies of primary lesions of patients [8-11].

HIF-1 $\alpha$ : a master regulator of innate immunity

The contribution of HIF- $1 \alpha$ to myeloid cell-mediated inflammatory pathologies prompted immediate consideration of the capability of the transcription factor to mediate central functions of macrophages and neutrophils in innate host defense. Whereas in healthy tissues, oxygen tension is
17.5-63 mm Hg (i.e., 2.5-9\% oxygen), much lower levels $(<1 \%$ oxygen) are present in wounds and tissue foci of infection. Many bacterial pathogens survive well and proliferate under anaerobic conditions, thus phagocytes must be adapted to function effectively in microbial eradication in the same microenvironments. Genetic experiments in which mouse phagocyte HIF-1 $\alpha$ levels were manipulated revealed the pivotal role of the transcriptional control pathway in phagocyte bactericidal activity.

Macrophages from mice deficient in HIF- $1 \alpha$ show diminished capacity to kill Gram-negative and Grampositive bacteria when compared to macrophages from wild-type littermates [7, 12], and HIF-1 $\alpha$ deficient animals were more susceptible to invasive skin infection produced by Streptococcus pyogenes. While HIF-1 $\alpha$ deletion (or overexpression through vHL elimination) did not alter phagocyte production of reactive oxygen species through the respiratory burst, the expression of a number of other molecular effectors of host innate defense was significantly correlated to HIF- $1 \alpha$ levels. These included cathelicidin antimicrobial peptides, the granule proteases cathepsin $G$ and elastase, tumor necrosis factor- $\alpha(\mathrm{TNF} \alpha)$, and nitric oxide (NO) produced by the inducible NO synthetase (iNOS) [12]. In addition to its microbicidal properties, NO is known to stabilize HIF- $1 \alpha$ by redistributing intracellular oxygen and inhibit prolyl hydroxylase activity [13], thereby setting up an autocrine feedback loop to amplify myeloid cell inflammatory activation.

A paradoxical result of these findings is that, due to HIF$1 \alpha$ activation, macrophages actually phagocytose and kill bacteria better under hypoxic conditions than they do under normoxic conditions $[12,14]$. Even more striking, bacterial exposure is a stronger stimulus for HIF- $1 \alpha$ stabilization than is hypoxia itself, and bacterial-induced HIF- $1 \alpha$ stabilization is readily demonstrated even at normoxia [12]. HIF-1 induces leukocyte $\beta 2$ integrin expression and thereby can promote neutrophils binding to epithelium [15], and inhibits neutrophil apoptosis via NF-KB activity $[16,17]$, thereby prolonging the effective window for these cells to participate in phagocytic killing. Upregulation of HIF- $1 \alpha$ has also been demonstrated during the differentiation of monocytes circulating in the blood to tissue bound macrophages [18].

Because circulating phagocytes serve a unique biological role, and must pass through radically different microenvironments upon their rapid mobilization to infected tissues, the HIF- $1 \alpha$ pathway represents an elegant control mechanism for the specialized functions of these cells (Fig. 1). Phagocyte bactericidal and proinflammatory capacities can be maintained in an "off" state while the myeloid cells circulate in the oxygen-rich bloodstream; and then be rapidly activated in response to the declining oxygen gradient encountered upon diapedesis and entry of 


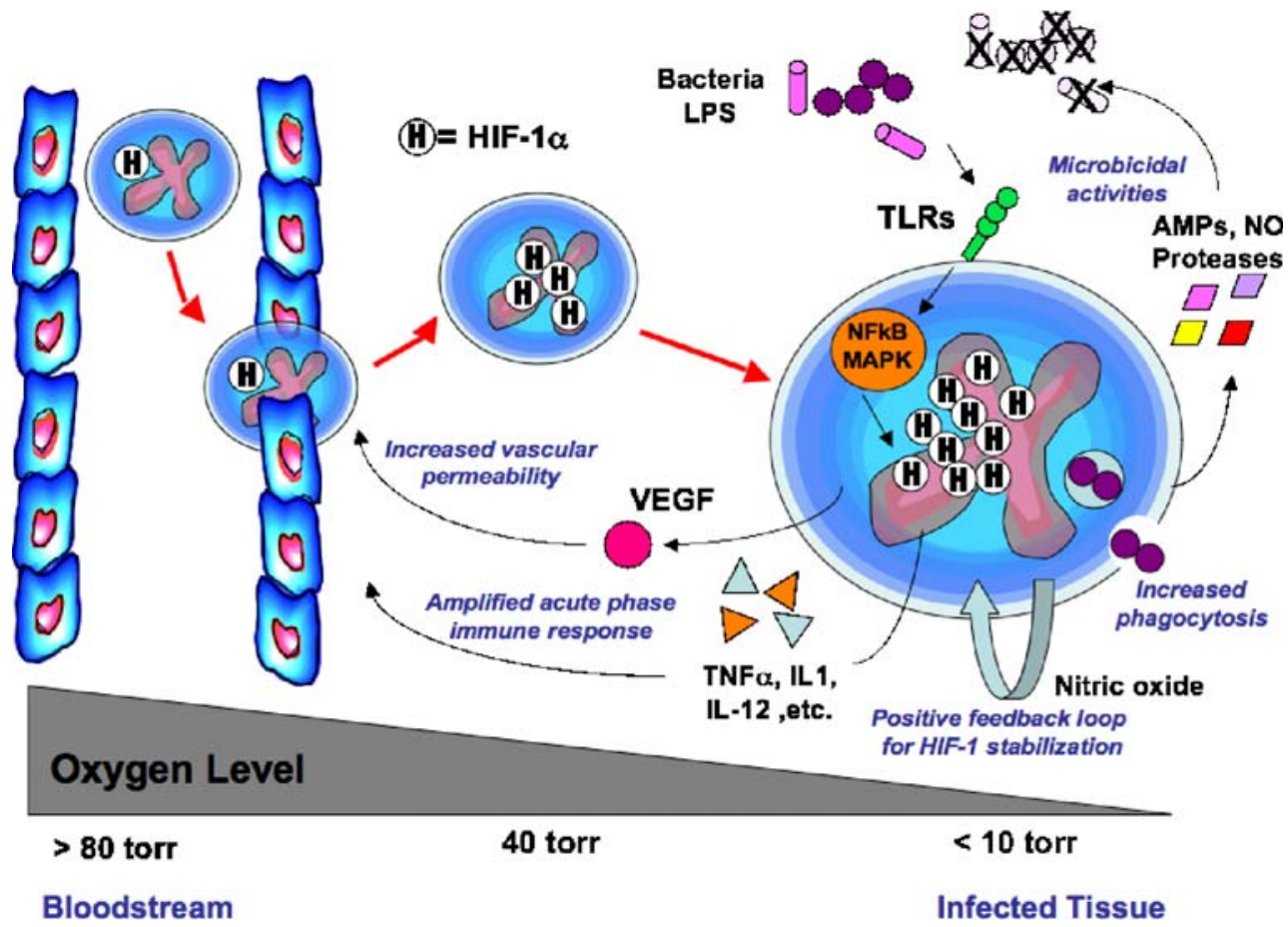

Fig. 1 Model for HIF-1 $\alpha$ transcriptional regulation of phagocyte innate immune functions. Phagocytic cells such as neutrophils and macrophages have low HIF- $1 \alpha$ levels when circulating in the oxygenrich bloodstream. When recruited to tissue foci of inflammation, they encounter a declining oxygen gradient which increases cellular HIF$1 \alpha$ levels and initiates activation of proinflammatory and bactericidal effector genes bearing HREs. Maximum activation is achieved on bacterial encounter, where HIF- $1 \alpha$ expression is further stimulated through pattern recognition receptors (e.g., TLR-4) and cell signaling pathways (e.g., NFkB, MAPK) just beginning to be elucidated. HIF-

$1 \alpha$ promotes increased phagocytosis and the release of antimicrobial peptides (e.g., cathelidicins) and granule proteases with direct microbicidal activities. Increased VEGF production and elaboration of proinflammatory cytokines facilitate recruitment and activation of additional immune effector cells. Activation of inducible nitric oxide (NO) synthetase generates a molecule (NO) with not only direct antimicrobial properties, but also the ability to further stabilize HIF-1 $\alpha$ and rapidly amplify the innate defense pathway in the phagocyte (modified and updated from [11])

the cells into the infected tissues. The primed phagocyte then encounters a further potent stimulation of the HIF- $1 \alpha$ transcriptonal pathway by direct encounter with the bacteria, as potentiated by the NO-mediated amplification loop. This regulatory mechanism underlying HIF- $1 \alpha$ control of target genes involved in microbial killing ensures that the corresponding inflammatory mediators are expressed preferentially in tissue foci of infection but not in healthy tissues where inflammatory damage might otherwise harm host cells.

New evidence indicates that HIF- $1 \alpha$ control of genes with innate immune functions may not be limited to phagocytic cell types, as conditional gene targeting and RNAi inhibition of HIF- $1 \alpha$ in skin keratinocytes decreased their production of antimicrobial peptides and intrinsic capability to control bacterial proliferation [19]. HIF-1 $\alpha$ transcriptional regulation also appears to modulate the production of proinflammatory cytokines in CD4+ and $\mathrm{CD} 8+\mathrm{T}$ lymphocytes, but in contrast to findings in macrophage and neutrophil lineages, the effect may be suppressive. After T-cell receptor activation, the release of $\mathrm{TNF} \alpha$ and interferon $\gamma$ (IFN $\gamma$ ) was increased in T cells with targeted deletion of the HIF- $1 \alpha$ gene compared to wild-type T cells [20]. The release of T cells from HIF-1 $\alpha$ suppression enhances their proliferation and allows them to contribute proinflammatory cytokine production and restrict bacterial proliferation in a cecal ligation puncture model [21].

Finally, it has recently been discovered that HIF- $1 \alpha$ transcriptional regulation mediates allelle expression phenotypes for the innate defense factor SLC11A1 (aka NRAMP1) through differential binding and activation of Z-DNA forming microsatellite polymorphisms in the SLC11A1 promotor [22]. Since these polymorphisms influence human susceptibility to tuberculosis, rheumatoid arthritis, Crohn's disease and other disorders, HIF- $1 \alpha$ may influence heritable variation in innate resistance to infection and inflammation within and between populations [22].

HIF- $1 \alpha$ activities during bacterial infection

Explorations of HIF- $1 \alpha$ function in activating neutrophil and macrophage bactericidal activities demonstrated increased levels of the transcription factor were stimulated in response 
to a variety of bacterial species including Streptococcus pyogenes, Streptococcus agalactiae, Staphylococcus aureus, Salmonella typhimurium and Pseudomonas aeruginosa [7, $12,22,23]$, suggesting it subserves a general role in bacterial/host interactions. Loss of myeloid cell HIF- $1 \alpha$ renders mice more susceptible to invasive $S$. pyogenes infection [12], and decreases phagocyte killing of Gramnegative and Gram-positive bacteria in vitro [7, 12, 23], suggesting that the HIF- $1 \alpha$ response pathway is broadly adaptive in host defense. In select additional research studies, the interplay between a specific bacterial infection and HIF$1 \alpha$ expression has been pursued in more detail.

One clear demonstration of HIF-1 $\alpha$ induction by a bacterial pathogen was provided in studies of Bartonella henselae, a facultative intracellular bacterium that causes cat-scratch disease and, in immunocompromised patients, the angioproliferative disorder known as bacillary angiomatosis (BA). Using HeLa as a model host cell line, $B$. henselae infection was found to induce HIF- $1 \alpha$ by Western blot and electrophoretic mobility shift assays, and immunoflourescence studies of BA lesions from human patients showed high levels of HIF-1 $\alpha$ expression [24]. Mutant studies suggest that pilus appendages on the $B$. henselae surface contribute to HIF- $1 \alpha$ activation, VEGF secretion and initiation of a proangiogenic program that characterizes BA tissue pathology [24]. Another intracellular pathogen, Chlamydia pneumoniae, appears to have evolved a unique mechanism to counteract HIF- $1 \alpha$ stabilization, thereby blunting innate immune function and promoting its own survival within host cells. During the later phase of intracellular chlamydial replication (48-72 h), secretion of the chlamydial protease-like activity factor into the host cell cytoplasm degraded accumulated HIF- $1 \alpha$, and this proteolytic activity was shown to play an essential role in $C$. pneumoniae replication during hypoxia [25].

Finally, the opportunistic pathogen $P$. aeruginosa has evolved mechanisms to sense alterations in host immune function and activation, and respond in a fashion that increases its virulence phenotypes, including expression of the PA-1 lectin/adhesin, a protein capable of inducing defects in host epithelial barrier function [26]. HIF-1 $\alpha$ is upregulated in intestinal epithelial cells exposed to hypoxia, and stimulates the release of adenosine, which normally exerts a cytoprotective function. $P$. aeruginosa is able to metabolize adenosine to inosine via adenosine deaminase, and both adenosine and inosine upregulate PA-1 lectin/ adhesin expression by the bacterium in a dose-dependent fashion [27]. In this sense, the pathogen senses HIF-1 $\alpha$ dependent changes in host cell function and subverts innate defense by virulence factor upregulation and metabolic elimination of a cytoprotective factor.

Since the mechanism of HIF- $1 \alpha$ turnover involves irondependent prolyl hydroxylase activity, it is conceivable that bacterial sequestration of iron could have the effect of HIF$1 \alpha$ stabilization. Preliminary data have emerged that this phenomenon may operate in the Peyer's patches of the intestine. Pathogens including Yersinia enterocolitica, Salmonella enterica or Enterobacter aerogenes induce HIF- $1 \alpha$ expression in Peyer's patches, and this induction can be replicated by application of purified siderophores (iron-binding proteins) from each species [28]. In contrast, siderophore-deficient bacterial mutants fail to induce HIF$1 \alpha$ activation. The disease potential of $Y$. enterocolitica is enhanced in mice deficient in intestinal HIF- $1 \alpha$ expression, suggesting this activation pathway contributes to host innate defense [28].

HIF-1 $\alpha$ dynamics in viral infection

Activation of HIF-1 $\alpha$ pathway during the life cycle of viral pathogens has been the subject of increasing investigation, revealing a diversity of functional outcomes in disease progression and critical linkages to viral oncogenesis. Viral infection is generally appreciated to induce stabilization of HIF- $1 \alpha$ in target cells, which consequently contributes to local inflammation. For example, the common upper respiratory tract pathogen respiratory syncytial virus (RSV) induces HIF- $1 \alpha$ in primary human bronchial epithelial cells via a NO-dependent pathway [29]. Increased HIF- $1 \alpha$ levels stimulates VEGF production, enhancing monolayer permeability, which may play a role in the airway edema of acute RSV infection.

In some cases, HIF-1 $\alpha$ may help coordinate a host defense program to limit cell damage secondary to viral infection. This scenario might particularly apply to viruses which exert an acute cytolytic effect, such as the vesicular stomatitis virus (VSV). Several years ago, it was noticed that hypoxia $\left(2 \% \mathrm{O}_{2}, 14 \mathrm{mmHg}\right)$ reduced the cytopathogenicity and replication of VSV, with measured antiviral effects of interferons $\alpha$ and $\gamma$ potentiated under the low oxygen conditions [30]. Interferons in turn have been shown to upregulate the expression of HIF-1 $\alpha$ [31]. The significance of HIF in the antiviral response to VSV was recently established by a pharmacological approach inhibition of HIF activity by a small molecule antagonist (chemotin) or RNA interference enhanced VSV cytotoxicity and replication, whereas the treatment with the hypoxia mimetic cobalt chloride promoted cellular resistance to infection [32]. Furthermore, expression profiling showed HIF enhancement of interferon $\beta$ and other antiviral genes during VSV infection [32].

For a number of persistent viral infections, when induction of HIF- $1 \alpha$ is insufficient to effect eradication, the accompanying proangiogenic program can contribute to oncogenesis. For example, chronic infections with the hepatitis $\mathrm{B}$ and $\mathrm{C}$ viruses (HBV and $\mathrm{HCV}$ ) are epidemio- 
logically associated with development of hepatocellular carcinoma (HCC), a highly vascularized solid tumor. The X protein of $\mathrm{HBV}(\mathrm{HBx})$ is felt to play an important role in angiogenesis and metastasis of HCC [33]. HIF- $1 \alpha$ levels and nuclear translocation are increased in cultured liver cells by expression of $\mathrm{HBx}$ via $\mathrm{p} 42 / \mathrm{p} 44$ mitogen-activated protein kinase (MAPK) pathways, leading to transcriptional activation of HIF- $1 \alpha$ target genes including VEGF, a finding corroborated in vivo in the livers of HBx transgenic mice [34]. Immunohistochemical studies in these mice reveal increased microvessels in dysplastic areas of liver where HIF-1 $\alpha$, VEGF, and HBx co-localize [35]. HBx was found to interact directly with the bHLH/PAS domain of HIF- $1 \alpha$, blocking its association with vHL and thus preventing its ubiquitin-mediated degradation [35]. Moreover, HIF- $1 \alpha$ activation induced by HBx was found to increase the multi-drug resistance 1 (MDR1) transporter activity in a hepatoma cell line, thereby contributing to increased resistance of the cancer cells to chemotherapeutic agents [36]. Recently, HCV infection has also been found to stabilize HIF- $1 \alpha$ with contributions from MAPK and other cellular activation pathways (NF-kB, STAT-3, PI3-K/AkT), stimulating VEGF production and neovascularization in a chick chorioallantioic membrane surrogate assay system [37].

Another example linking viral activation of HIF- $1 \alpha$ to proangiongenesis and tumor development can be found in the case of human papillomavirus-16 (HPV-16), an etiologic agent of cervical interstitial neoplasia that, undetected, can progress to cervical carcinoma. In advanced cervical cancer lesions, many of which are hypoxic, increased HIF$1 \alpha$ levels can be correlated to poor prognosis $[38,39]$. Transgenic mice expressing HPV-16 in cervical epithelium under control of the K14 promotor can develop locally invasive cervical cancers; the size of these lesions is increased 70-fold when double transgenic mice are created with both HPV-16 and HIF-1 $\alpha$ expression driven by K14 [40]. Transfection of human cervical cancer cell lines with HPV-16 oncoproteins E6 and E7 can induce VEGF expression and capillary formation in vitro; however, this proangiogenic effect is abolished when the cells are cotransfected with siRNA targeting HIF-1 $\alpha$ [41]. Together, these new studies suggest a synergism of HIF- $1 \alpha$ with viral ongogenes in premalignant lesions to promote gene activation programs favoring neovascularization and cancer development.

HIF- $1 \alpha$ activation is apparent during other viral infections associated with risk of neoplastic transformation. The retrovirus human T-cell leukemia virus type 1 (HTLV-1) causes adult T-cell leukemia. Increased HIF-1 $\alpha$ protein levels and VEGF expression are detected in T-cell lines infected with HTLV-1, via a process involving activation of PI3K/Akt signaling by the HTLV-1 protein Tax [42]. The herpesvirus Epstein Barr virus (EBV) is linked to develop- ment of nasopharyngeal carcinoma in specific populations. The major oncoprotein of EBV, latent membrane protein 1 (LMP1), increases HIF-1 $\alpha$ levels and stimulates VEGF expression in nasopharyngeal epithelial cells through a mechanism dependant both upon $\mathrm{H}_{2} \mathrm{O}_{2}$ production and $\mathrm{p} 42 /$ p44 MAPK activity [43]. Recent co-immunoprecipation studies indicate EBV LMP1 enhances the stability of Siah1 E3 ubiquitin ligase, inducing proteasomal degradation of PHD-1 and PHD-3 that normally tag HIF- $1 \alpha$ for degradation. LMP1 thus prevents formation of the VHL/HIF- $1 \alpha$ complex, providing a mechanism for HIF- $1 \alpha$ stabilization during EBV nasopharyngeal cell infection [44].

A fascinating crosstalk between viral genes and the HIF$1 \alpha$ pathway has recently been elucidated for the human herpesvirus 8 (HHV-8). Latent infection with HHV-8 is associated with the endothelial tumor Kaposi's sarcoma (KS) in AIDS patients and others with lowered immunity, and KS lesions in vivo are associated with high levels of both the HIF- $1 \alpha$ and HIF- $2 \alpha$ protein [45]. HHV-8 infection of endothelial cells in vitro leads to increased stabilization of the two HIF $\alpha$ subunits and increased HIF-responsive gene expression [45]. The HHV-8 latency-associated nuclear antigen (LANA), which plays a critical role in modulating viral and target cell gene expression, increases HIF- $1 \alpha$ mRNA levels, and also physically interacts with the transcription factor to enhance its promoter activities [46]. HIF- $1 \alpha$ induction and co-activation during HHV8 infection can then lead to activation of target genes in the genome of the virus itself, including that encoding Rta, which is involved in transition of the virus from latency to a lytic replication phase. Several putative HREs are identified in the essential Rta promoter, and HIF- $1 \alpha$-dependent binding of a LANA protein complex to such HREs can be demonstrated by electromobility shift assays [46]. In another potential example of viral-HIF crosstalk, replication of parvovirus B19, a cause of erythema infectiousum or "fifth disease", is enhanced under hypoxic conditions. HIF$1 \alpha$ binding to an HRE located in the B19 promoter region can be demonstrated; however, the full implications of this finding for viral pathogenesis remain unclear [47].

\section{HIF- $1 \alpha$ modulation in parasitic infection}

Though much less well studied, induction of HIF- $1 \alpha$ also appears to occur in the context of infection with protozoan parasites. For example, cutaneous lesions can be generated in BALB/c mice by infection with Leishmania amazonensis, and in the later stages of infection, HIF-1 $\alpha$ induction in the cytoplasm and parasitophorous vacuoles of macrophages recruited to the microenvironment can be clearly demonstrated [48]. An interesting comparative microarray analysis of transcriptional activation patterns in human fibroblasts infected with the obligate intracellular parasites Toxoplasma 
gondii and Trypanosoma cruzi has identified an important role for HIF-1 $\alpha$ in the life cycle of the former. T. gondii, a cause of opportunistic infections in fetuses and the immunocompromised, induced transcripts for glycolytic enzymes, glucose transporters, transferrin receptor and VEGF, a transcriptome signature for HIF- $1 \alpha$ activation $[49,50]$, whereas parallel fibroblast infection studies with T. cruzi produced minimal changes in expression profile [51]. Further investigation showed $T$. gondii infection rapidly induced levels of HIF- $1 \alpha$ and activated reporter gene expression in infected fibroblasts [52]. Under hypoxic conditions (3\% oxygen) present in the tissues (brain, muscle, retina) in which the parasite produces serious disease, $T$. gondii cell division and organelle maintenance was severely impaired in host cells where HIF-1 $\alpha$ function was deleted. The $T$. gondii parasite may have evolved to induce HIF- $1 \alpha$ because a target gene is essential to parasite growth, or alternatively because HIF- $1 \alpha$ activation is necessary to preserve the health of the host cell in which the parasite has become established [52].

HIF- $1 \alpha$ and sepsis

Sepsis reflects a maladaptive and potentially lethal host response to infection, in which bacteria or lipopolysaccharide (LPS) act as potent activators of uncontrolled proinflammatory cytokine release from immune cells including monocytes and macrophages. LPS raises levels of HIF- $1 \alpha$ in macrophages through activities of the p42/44 MAPK and $\mathrm{NfkB}$ signal transduction pathways [53] and in hepatocytes by JNK signaling and c-Jun activation [54]. Recently, it has been shown that LPS increases HIF- $1 \alpha$ and decreases prolyl hydroxylase mRNA production through a process that depends upon LPS pattern recognition by Toll-like receptor 4 (TLR-4) [55]. Studies of LPS challenge in mice with conditional gene targeting of HIF- $1 \alpha$ in the myeloid lineage reveal HIF- $1 \alpha$ to be a critical determinant of the sepsis phenotype, promoting high level production of inflammatory cytokines TNF- $\alpha$, interleukin-1 (IL-1), IL-6, and IL-12. HIF-1 $\alpha$ deletion in the macrophage lineage is protective against LPS-induced mortality and blocks development of clinical indicators of sepsis including hypothermia, tachycardia, and hypotension [55].

HIF-1 $\alpha$ : a therapeutic target for infectious diseases?

We have summarized above an evolving view of HIF- $1 \alpha$ as a master regulator of the innate immune function of phagocytes [12, 56, 57]. Since pharmacological approaches for manipulating HIF-1 $\alpha$ levels have been considered extensively in the context of cancer therapy and angiogenesis $[58,59]$, the possibility is raised of a novel approach to therapy of infectious disease conditions, namely boosting the bactericidal capacity of phagocytes [60]. Conceptual support for this concept was provided by in vitro studies where genetic augmentation of macrophage HIF- $1 \alpha$ levels (through vHL deletion) or addition of a series of pharmacological agonists of HIF-1 $\alpha$ (hypoxia mimetics that restrict prolyl hydroxylase access to iron), each enhanced murine macrophage bactericidal activity [12]. Similarly, dose-dependent enhancement of the bactericidal activity of human whole blood, neutrophils, and macrophage cell line U937 against the pathogen Staphylcococcus aureus was achieved using the HIF-1 $\alpha$ agonist L-mimosine [23]. Local treatment with L-mimosine also significantly delayed the progression of $S$. aureus skin abscesses in a murine challenge model [23].

The proof-of-principle experiments described suggest further exploration of HIF- $1 \alpha$ augmentation to boost innate defense function. This may be of interest as a therapeutic strategy in infectious disease conditions complicated by antibiotic resistance or compromised host immunity (e.g. AIDS, cancer chemotherapy). An advantage of targeting host molecules that enhance phagocyte recruitment or activate array of phagocyte bactericidal mechanisms is lack of selective pressure for resistance - the bacterial pathogen cannot evolve to combat a drug that targets the host and effectively deploys a multifaceted combination therapy of natural antimicrobial molecules [61]. Coincidently, HIF-1 $\alpha$ agonist therapy may benefit the anemia that can accompany chronic infection, since it functions in the liver to suppress production of the peptide hepcidin, promoting iron absorption and mobilization, and stimulates red blood cell synthesis by increasing EPO production [62]. Finally, strategies to inhibit HIF- $1 \alpha$ in therapy of chronic inflammatory disorder such as rheumatoid arthritis may provide a safer therapeutic margin than high-dose steroids or cytotoxic agents, since rapid posttranslational regulation of HIF$1 \alpha$ levels could allow rapid restoration of innate immune function of phagocytes upon drug withdrawal in the event of opportunistic infection.

Acknowledgment The author's own research contributions in the area of HIF- $1 \alpha$ and innate immunity have been supported by NIH grant AI060840 (to RSJ and VN) and Swiss National Foundation Fellowship PASMA-117303 (to ASZ).

Conflict of interest statement The authors declare no conflict of interest.

\section{References}

1. Saadi S, Wrenshall LE, Platt JL (2002) Regional manifestations and control of the immune system. FASEB J 16:849-856

2. Schor H, Vaday GG, Lider O (2000) Modulation of leukocyte behavior by an inflamed extracellular matrix. Dev Immunol 7:227-238 
3. Semenza GL, Roth PH, Fang HM, Wang GL (1994) Transcriptional regulation of genes encoding glycolytic enzymes by hypoxia-inducible factor 1. J Biol Chem 269:23757-23763

4. Iyer NV, Kotch LE, Agani F, Leung SW, Laughner E, Wenger RH, Gassmann M, Gearhart JD, Lawler AM, Yu AY, Semenza GL (1998) Cellular and developmental control of O2 homeostasis by hypoxia-inducible factor $1 \alpha$. Genes Dev 12:149-162

5. Ryan HE, Lo J, Johnson RS (1998) HIF-1 $\alpha$ is required for solid tumor formation and embryonic vascularization. EMBO J 17:3005-3015

6. Kotch LE, Iyer NV, Laughner E, Semenza GL (1999) Defective vascularization of HIF- $1 \alpha$-null embryos is not associated with VEGF deficiency but with mesenchymal cell death. Dev Biol 209:254-267

7. Cramer T, Yamanishi Y, Clausen BE, Forster I, Pawlinski R, Mackman N, Haase VH, Jaenisch R, Corr M, Nizet V, Firestein GS, Gerber HP, Ferrara N, Johnson RS (2003) HIF-1 $\alpha$ is essential for myeloid cell-mediated inflammation. Cell 112:645-657

8. Westra J, Brouwer E, Bos R, Posthumus MD, Doornbos-van der Meer B, Kallenberg CG, Limburg PC (2007) Regulation of cytokine-induced HIF-1 $\alpha$ expression in rheumatoid synovial fibroblasts. Ann N Y Acad Sci 1108:340-348

9. Gaber T, Dziurla R, Tripmacher R, Burmester GR, Buttgereit F (2005) Hypoxia inducible factor (HIF) in rheumatology: low O2! See what HIF can do. Ann Rheum Dis 64:971-980

10. Hollander AP, Corke KP, Freemont AJ, Lewis CE (2001) Expression of hypoxia-inducible factor $1 \alpha$ by macrophages in the rheumatoid synovium: implications for targeting of therapeutic genes to the inflamed joint. Arthritis Rheum 44:1540-1544

11. Vink A, Schoneveld AH, Lamers D, Houben AJ, van der Groep P, van Diest PJ, Pasterkamp G (2007) HIF-1a expression is associated with an atheromatous inflammatory plaque phenotype and upregulated in activated macrophages. Atherosclerosis (in press)

12. Peyssonnaux C, Datta V, Cramer T, Doedens A, Theodorakis EA, Gallo RL, Hurtado-Ziola N, Nizet V, Johnson RS (2005) HIF1alpha expression regulates the bactericidal capacity of phagocytes. J Clin Invest 115:1806-1815

13. Hagen T, Taylor CT, Lam F, Moncada S (2003) Redistribution of intracellular oxygen in hypoxia by nitric oxide: effect on HIF $1 \alpha$. Science 302:1975-1978

14. Anand RJ, Gribar SC, Li J, Kohler JW, Branca MC, Dubowski T, Sodhi CP, Hackam DJ (2007) Hypoxia causes an increase in phagocytosis by macrophages in a HIF-1a-dependent manner. J Leuk Biol 82:1257-1265

15. Kong T, Eltzschig HK, Karhausen J, Colgan SP, Shelley CS (2004) Leukocyte adhesion during hypoxia is mediated by HIF-1dependent induction of $\beta 2$ integrin gene expression. Proc Natl Acad Sci USA 101:10440-10445

16. Walmsley SR, Print C, Farahi N, Peyssonnaux C, Johnson RS, Cramer T, Sobolewski A, Condliffe AM, Cowburn AS, Johnson N, Chilvers ER (2005) Hypoxia-induced neutrophil survival is mediated by HIF- $1 \alpha$-dependent NF-kB activity. J Exp Med 201:105-115

17. Walmsley SR, Cowburn AS, Clatworthy MR, Morrell NW, Roper EC, Singleton V, Maxwell P, Whyte MK, Chilvers ER (2006) Neutrophils from patients with heterozygous germline mutations in the von Hippel Lindau protein (VHL) display delayed apoptosis and enhanced bacterial phagocytosis. Blood 108:3176-3178

18. Oda T, Hirota K, Nishi K, Takabuchi S, Oda S, Yamada H, Arai T, Fukuda K, Kita T, Adachi T, Semenza GL, Nohara R (2006) Activation of hypoxia-inducible factor 1 during macrophage differentiation. Am J Physiol 291:C104-113

19. Peyssonnaux C, Boutin A, Zinkernagel AS, Datta V, Nizet V, Johnson RS (2007) Critical role of HIF-1a in keratinocyte defense against bacterial infection. J Invest Derm (in press)
20. Lukashev D, Klebanov B, Kojima H, Grinberg A, Ohta A, Berenfeld L, Wenger RH, Ohta A, Sitkovsky M (2006) Cutting edge: hypoxia-inducible factor $1 \alpha$ and its activation-inducible short isoform I.1 negatively regulate functions of CD4+ and CD8+ T lymphocytes. J Immunol 177:4962-4965

21. Thiel M, Caldwell CC, Kreth S, Kuboki S, Chen P, Smith P, Ohta A, Lentsch AB, Lukashev D, Sitkovsky MV (2007) Targeted deletion of HIF- $1 \alpha$ gene in $\mathrm{T}$ cells prevents their inhibition in hypoxic inflamed tissues and improves septic mice survival. PLoS ONE 2: e853

22. Bayele HK, Peyssonnaux C, Giatromanolaki A, Arrais-Silva WW, Mohamed HS, Collins H, Giorgio S, Koukourakis M, Johnson RS, Blackwell JM, Nizet V, Srai SK (2007) HIF-1 regulates heritable variation and allele expression phenotypes of the macrophage immune response gene SLC11A1 from a Z-DNA forming microsatellite. Blood 110:3039-3048

23. Zinkernagel AS, Peyssonnaux C, Johnson RS, Nizet V (2007) Pharmacologic augmentation of HIF-1a with mimosine boosts the bactericidal capacity of phagocytes. J Infect Dis (in press)

24. Kempf VA, Lebiedziejewski M, Alitalo K, Walzlein JH, Ehehalt U, Fiebig J, Huber S, Schutt B, Sander CA, Muller S, Grassl G, Yazdi AS, Brehm B, Autenrieth IB (2005) Activation of hypoxia-inducible factor-1 in bacillary angiomatosis: evidence for a role of hypoxia-inducible factor-1 in bacterial infections. Circulation 111:1054-1062

25. Rupp J, Gieffers J, Klinger M, van Zandbergen G, Wrase R, Maass M, Solbach W, Deiwick J, Hellwig-Burgel T (2007) Chlamydia pneumoniae directly interferes with HIF-1a stabilization in human host cells. Cell Microbiol 9:2181-2191

26. Wu L, Estrada O, Zaborina O, Bains M, Shen L, Kohler JE, Patel N, Musch MW, Chang EB, Fu YX, Jacobs MA, Nishimura MI, Hancock RE, Turner JR, Alverdy JC (2005) Recognition of host immune activation by Pseudomonas aeruginosa. Science 309:774-777

27. Patel NJ, Zaborina O, Wu L, Wang Y, Wolfgeher DJ, Valuckaite V, Ciancio MJ, Kohler JE, Shevchenko O, Colgan SP, Chang EB, Turner JR, Alverdy JC (2007) Recognition of intestinal epithelial HIF-1alpha activation by Pseudomonas aeruginosa. Am J Physiol Gastrointest Liver Physiol 292:G134-142

28. Werth N, Hartmann H, Wurz H, Amr A, Kempf VA (2006) Role of HIF-1 in bacterial infections. Acta Physiologica 188:P23

29. Kilani MM, Mohammed KA, Nasreen N, Tepper RS, Antony VB (2004) RSV causes HIF-1alpha stabilization via NO release in primary bronchial epithelial cells. Inflammation 28:245-251

30. Naldini A, Carraro F, Fleischmann WR Jr., Bocci V (1993) Hypoxia enhances the antiviral activity of interferons. J Interferon Res 13:127-132

31. de Veer MJ, Holko M, Frevel M, Walker E, Der S, Paranjape JM, Silverman RH, Williams BR (2001) Functional classification of interferon-stimulated genes identified using microarrays. J Leuk Biol 69:912-920

32. Hwang II, Watson IR, Der SD, Ohh M (2006) Loss of VHL confers hypoxia-inducible factor (HIF)-dependent resistance to vesicular stomatitis virus: role of HIF in antiviral response. J Virol 80:10712-10723

33. Wang XW, Forrester K, Yeh H, Feitelson MA, Gu JR, Harris CC (1994) Hepatitis B virus X protein inhibits p53 sequence-specific DNA binding, transcriptional activity, and association with transcription factor ERCC3. Proc Natl Acad Sci USA 91:2230-2234

34. Yoo YG, Oh SH, Park ES, Cho H, Lee N, Park H, Kim DK, Yu DY, Seong JK, Lee MO (2003) Hepatitis B virus X protein enhances transcriptional activity of hypoxia-inducible factor- $1 \alpha$ through activation of mitogen-activated protein kinase pathway. J Biol Chem 278:39076-39084

35. Moon EJ, Jeong CH, Jeong JW, Kim KR, Yu DY, Murakami S, Kim CW, Kim KW (2004) Hepatitis B virus X protein induces 
angiogenesis by stabilizing hypoxia-inducible factor- $1 \alpha$. FASEB $\mathrm{J}$ $18: 382-384$

36. Han HK, Han CY, Cheon EP, Lee J, Kang KW (2007) Role of hypoxia-inducible factor- $1 \alpha$ in hepatitis-B-virus $\mathrm{X}$ protein-mediated MDR1 activation. Biochem Biophys Res Commun 357:567-573

37. Nasimuzzaman M, Waris G, Mikolon D, Stupack DG, Siddiqui A (2007) Hepatitis $\mathrm{C}$ virus stabilizes hypoxia-inducible factor- $1 \alpha$ $(\mathrm{HIF}-1 \alpha)$ and stimulates the synthesis of vascular endothelial growth factor (VEGF). J Virol 81:10249-10257

38. Hockel M, Schlenger K, Aral B, Mitze M, Schaffer U, Vaupel P (1996) Association between tumor hypoxia and malignant progression in advanced cancer of the uterine cervix. Cancer Res 56:4509-4515

39. Birner P, Schindl M, Obermair A, Plank C, Breitenecker G, Oberhuber G (2000) Overexpression of hypoxia-inducible factor $1 \alpha$ is a marker for an unfavorable prognosis in early-stage invasive cervical cancer. Cancer Res 60:4693-4696

40. Lu ZH, Wright JD, Belt B, Cardiff RD, Arbeit JM (2007) Hypoxiainducible factor-1 facilitates cervical cancer progression in human papillomavirus type 16 transgenic mice. Am J Pathol 171:667-681

41. Tang X, Zhang Q, Nishitani J, Brown J, Shi S, Le AD (2007) Overexpression of human papillomavirus type 16 oncoproteins enhances hypoxia-inducible factor $1 \alpha$ protein accumulation and vascular endothelial growth factor expression in human cervical carcinoma cells. Clin Cancer Res 13:2568-2576

42. Tomita M, Semenza GL, Michiels C, Matsuda T, Uchihara JN, Okudaira T, Tanaka Y, Taira N, Ohshiro K, Mori N (2007) Activation of hypoxia-inducible factor 1 in human T-cell leukaemia virus type 1 -infected cell lines and primary adult Tcell leukaemia cells. Biochem J 406:317-323

43. Wakisaka N, Kondo S, Yoshizaki T, Murono S, Furukawa M, Pagano JS (2004) Epstein-Barr virus latent membrane protein 1 induces synthesis of hypoxia-inducible factor $1 \alpha$. Mol Cell Biol 24:5223-5234

44. Kondo S, Seo SY, Yoshizaki T, Wakisaka N, Furukawa M, Joab I, Jang KL, Pagano JS (2006) EBV latent membrane protein 1 upregulates hypoxia-inducible factor $1 \alpha$ through Siah1-mediated down-regulation of prolyl hydroxylases 1 and 3 in nasopharyngeal epithelial cells. Cancer Res 66:9870-9877

45. Carroll PA, Kenerson HL, Yeung RS, Lagunoff M (2006) Latent Kaposi's sarcoma-associated herpesvirus infection of endothelial cells activates hypoxia-induced factors. J Virol 80:10802-10812

46. Cai Q, Lan K, Verma SC, Si H, Lin D, Robertson ES (2006) Kaposi's sarcoma-associated herpesvirus latent protein LANA interacts with HIF- $1 \alpha$ to upregulate RTA expression during hypoxia: Latency control under low oxygen conditions. J Virol 80:7965-7975

47. Pillet S, Le Guyader N, Hofer T, NguyenKhac F, Koken M, Aubin JT, Fichelson S, Gassmann M, Morinet F (2004) Hypoxia enhances human B19 erythrovirus gene expression in primary erythroid cells. Virology 327:1-7

48. Arrais-Silva WW, Paffaro VA Jr., Yamada AT, Giorgio S (2005) Expression of hypoxia-inducible factor- $1 \alpha$ in the cutaneous lesions of BALB/c mice infected with Leishmania amazonensis. Exp Mol Pathol 78:49-54

49. Gail M, Gross U, Bohne W (2001) Transcriptional profile of Toxoplasma gondii-infected human fibroblasts as revealed by gene-array hybridization. Mol Genet Genomics 265:905-912

50. Blader IJ, Manger ID, Boothroyd JC (2001) Microarray analysis reveals previously unknown changes in Toxoplasma gondiiinfected human cells. J Biol Chem 276:24223-24231

51. Vaena de Avalos S, Blader IJ, Fisher M, Boothroyd JC, Burleigh BA (2002) Immediate/early response to Trypanosoma cruzi infection involves minimal modulation of host cell transcription. J Biol Chem 277:639-644

52. Spear W, Chan D, Coppens I, Johnson RS, Giaccia A, Blader IJ (2006) The host cell transcription factor hypoxia-inducible factor 1 is required for Toxoplasma gondii growth and survival at physiological oxygen levels. Cell Microbiol 8:339-352

53. Frede S, Stockmann C, Freitag P, Fandrey J (2006) Bacterial lipopolysaccharide induces HIF-1 activation in human monocytes via p44/42 MAPK and NF-kB. Biochem J 396:517-527

54. Kim HY, Kim YH, Nam BH, Kong HJ, Kim HH, Kim YJ, An WG, Cheong J (2007) HIF-1 $\alpha$ expression in response to lipopolysaccaride mediates induction of hepatic inflammatory cytokine TNF $\alpha$. Exp Cell Res 313:1866-1876

55. Peyssonnaux C, Cejudo-Martin P, Doedens A, Zinkernagel AS, Johnson RS, Nizet V (2007) Cutting edge: Essential role of hypoxia inducible factor- $1 \alpha$ in development of lipopolysaccharide-induced sepsis. J Immunol 178:7516-7519

56. Cramer T, Johnson RS (2003) A novel role for the hypoxia inducible transcription factor HIF-1a: critical regulation of inflammatory cell function. Cell Cycle 2:192-193

57. Strieter RM (2003) Mastering innate immunity. Nat Med 9:512-513

58. Semenza GL (2003) Targeting HIF-1 for cancer therapy. Nat Rev Cancer 3:721-732

59. Semenza GL (2006) Development of novel therapeutic strategies that target HIF-1. Exp Opin Therapeut Targets 10:267-280

60. Zarember KA, Malech HL (2005) HIF-1 $\alpha$ : a master regulator of innate host defenses. J Clin Invest 115:1702-1704

61. Nizet V (2007) Understanding how leading bacterial pathogens subvert innate immunity to reveal novel therapeutic targets. J Allergy Clin Immunol 120:13-22

62. Peyssonnaux C, Zinkernagel AS, Scheupbach RA, Rankin E, Vaulont S, Haase VH, Nizet V, Johnson RS (2007) Regulation of iron homeostasis by the hypoxia inducible transcription factors (HIF). J Clin Invest 117:1926-1932 